\title{
Print Journal Holdings in Two Canadian Consortial Projects
}

\author{
Andrew Waller
}

Andrew Waller is Serials Librarian, University of Calgary, Calgary, AB (E-mail: waller@ucalgary.ca).

This paper was originally presented at the Canadian Library Association Collection Development \& Management Interest Group Pre-Conference Session on the Future of Collections Work in Canadian Libraries, June 19, 2002.

\begin{abstract}
The Canadian university library members of two consortial ejournal arrangements were surveyed to determine how many of the corresponding print journals had been cancelled as a result of participation in the online packages. The survey results indicated that the number of current print subscriptions held by the libraries had notably decreased. This paper discusses this loss of print and presents two options, with examples, for dealing with the archiving of print journals, Distributed Print Archiving and Back-up Repositories. The question of whether anything really needs to be done is also addressed.
\end{abstract}

KEYWORDS. Print journals, electronic journals, cancellations, archiving, academic libraries

\section{Introduction}

As academic libraries have become more involved in consortial purchases of ejournal packages, there has been much discussion in the literature and elsewhere relating to various merits and drawbacks of the so-called "Big Deal". One aspect that seems not to have been talked about much is what is happening to the print subscriptions overlapped by these large e-journal bundles.

Numerous articles in the last few years have detailed how some libraries have made the move to e-journal or largely e-journal-only collections (perhaps the best documented example of this is the work carried out at Drexel University ${ }^{1}$ ). However, there has been less reporting from the print perspective. Are print subscriptions being retained? How much print is being retained and how much is being cancelled? How accessible are the cancelled or superceded print journals? Are they being moved to storage? These questions raise a number of issues for access services.

This paper examines these questions by presenting the results of a short survey of the university libraries participating in two Canadian consortial deals, the first part of the Canadian National Site Licensing Project (CNSLP) and the Harcourt Health Sciences journal collection agreement. A brief picture of the 
situation regarding the print holdings is presented along with some implications of the retention decisions made by the participants.

\section{CNSLP and the Harcourt Health Sciences Deal}

Before moving on, a brief description of the two consortial arrangements studied here is required.

The Canadian National Site Licensing Project (CNSLP) is a Canada-wide consortium designed to increase the access to research article literature in Canadian universities. The members are made up all Canadian university libraries, 64 in total. The first agreements with publishers, all for five years, took effect in 2001 and provided access for consortium members to the online journals of Academic Press (the IDEAL service), the American Chemical Society (ACS), the Institute of Physics (IOP), the Royal Society of Chemistry (RSC), and Springer (the LINK service) ${ }^{2}$. CNSLP is funded for the first three years by a combination of money from the federal Canadian Foundation for Innovation (CFI) and various provincial and local sources.

The Harcourt Health Sciences deal is of a similar nature to CNSLP. It is a consortial arrangement with the Association of Canadian Medical Colleges and the Consortium of Ontario Academic Health Libraries to provide access to all the Harcourt Health Sciences journals. The participants surveyed were the 15 Canadian medical school libraries, all of which are associated with universities. The Harcourt deal came into place early in 2002.

\section{Why Were These Projects Selected?}

There are many consortial arrangements that could have been investigated in this study. However, the CNSLP and Harcourt deals were selected for study for a number of reasons:

- They are large in scale, providing access to many fulltext electronic journals. The CNSLP packages comprise over 700 titles while the Harcourt deal includes about 160 titles.

- They are publisher-based and are not third party aggregators (such as ProQuest, Academic Search Premier, and numerous others). Many of the issues related to third party aggregators are closely-related but aggregators also exhibit unique problems.

- Print is unbundled from electronic. Participating libraries are free to do whatever they wish with print subscriptions that have online counterparts 
(keep, cancel, put into storage, etc.). There is a discount of $75 \%$ off the subscription price for any print that is retained.

- There is an "archival component", at least with the CNSLP license. If the contract were not to be renewed, the participating libraries would have perpetual access to the content in the license period.

- They are of a recent nature. Both deals are no more than two years old.

In addition, the author is familiar with these projects, especially CNSLP.

\section{The Survey}

The genesis of this study was the rumor passing through the Canadian university library community in early 2002 that drastic decisions were being made regarding the print journals duplicated in online packages. In particular, stories were circulating that the libraries involved in the Harcourt deal were being particularly aggressive in cutting their print subscriptions.

Feeling that this merited further investigation, the author, acting as an individual researcher, sent a short message in January 2002 to the CNSLP email list (most of the contacts for each institution on this list are collections librarians) asking two simple questions of each of the 64 participating libraries:

1) Are you canceling or keeping your print journal subscriptions duplicated in the CNSLP e-journal package?

2) If you are not retaining the print journals, are you leaving the backsets on the shelves or are you putting the backsets into storage?

The results from this first set of questions, which will be discussed in the next section, prompted more detailed investigation. In June 2002, messages were sent to the CNSLP email list and to the 15 libraries participating in the Harcourt project requesting more specific information, via the Association of Canadian Medical Colleges libraries email list. On Excel spreadsheets with lists of the electronic journals acquired in the two deals, both groups were asked to indicate the following:

- If a library held a current print subscription before CNSLP.

- If a library cancelled the print subscription or planned to do so soon.

- If a library moved backset print journals to storage or planned to do so soon. 
The aim of these questions was to get a title-by-title look at what had happened to the print Harcourt and CNSLP journals at the various participating institutions. It might be possible to follow the holdings of some key titles in the packages. If pressed for time, respondents could also just submit summaries (e.g. Library $X$ had 100 print subscriptions from CNSLP publishers before the deal took shape; after CNSLP, they had 20).

Looking for some qualitative responses, two other questions were asked:

1) If your library has cancelled any CNSLP print subscriptions, what were the reasons?

2) If your library has moved any CNSLP print journals to storage, what were the reasons?

The full survey questions, accompanying spreadsheets, and related information are included in Appendix One.

\section{Survey Results, Part One}

The short survey from the beginning of 2002 produced the following results.

- $27 \%$ of the participating institutions responded.

- $65 \%$ of the responding institutions had cancelled or soon would cancel all or most of the CNSLP print subscriptions.

Several respondents gave financial concerns as a major reason for not retaining print journals. Chiefly, they required the money for their continued participation in CNSLP. Savings from not having to bind and store print journals was also mentioned.

Some libraries indicated that they had an official policy canceling print subscriptions where stable electronic counterparts are available. Most other libraries stated that they were working on policies to deal with the print vs. electronic retention issue. In some cases, different library branches in the same institution had different practices e.g. a Medical library might cancel print while an Arts and Humanities library might keep print.

- $24 \%$ of the responding institutions that would likely be canceling the print but closer to the end of the initial CNSLP period.

Some of these libraries indicated that canceling the print CNSLP journals would likely be part of an "exit" strategy, employing the savings from the cancelled print subscriptions to sustain their participation in CNSLP when the CFI funding ends. 


\section{Survey Results, Part Two - CNSLP}

The more detailed survey of the CNSLP participants from a few months later brought in similar results.

\section{- $31 \%$ of the participating institutions responded in some way.}

\section{Quantitative Responses}

All the responding libraries had some subscriptions to print journals from participating publishers before CNSLP started. These numbers ranged from 6 to 449 journals, with an average of 128 per library.

The figures for cancellations indicated that some drastic cancellations of print titles had occurred. The average number of print holdings cancelled was $75 \%$. Just over a third of the responding libraries had cancelled $100 \%$ of their print CNSLP subscriptions. $65 \%$ of respondents had cancelled $90 \%$ or more. Only $18 \%$ had kept all or almost all print titles

Looking at storage, nearly all the responding libraries had not sent any print to storage; only one library had done so.

\section{Qualitative Responses}

The question asking for the reasons behind cancellation decisions produced similar results to those gathered in the casual survey at the start of 2002. Once more, finances were given as a major motivator; participating libraries wanted to have money to pay for CNSLP in the future and also didn't want to pay for content twice by keeping two formats of the same journals. Again, having a formal policy to drop print journals in favor of e-journals was mentioned as a reason as were supporting the move to the electronic journal and freeing up shelf space.

The question about storage revealed that most libraries had not moved cancelled backsets to storage. Some libraries don't have storage options but most of those that do are considering moving the cancelled material. At least for the short term, there is no evidence that space needs was a primary factor in the cancellations (though space concerns have prompted print cancellations elsewhere, such as at the University of Texas at Dallas ${ }^{3)}$. The net result, then, would be large runs of non-current journals in the open stacks, with brief periods of overlap between print and online holdings, and then electronic-only after a certain point. 


\section{Individual CNSLP Journals}

One of the aims of this survey was to look at what has happened to the print subscriptions of specific journals in the CNSLP member libraries. To this end, the author asked the subject librarians at the University of Calgary Library to select a few important titles for their disciplines from the CNSLP package. This resulted in a list of 38 journals that was compared to the data provided by the responding libraries.

\section{TABLE 1. Pre- and Post-Cancellation Holdings for Some Key CNSLP} Journals

\begin{tabular}{|c|c|c|c|c|}
\hline Title & Discipline & Before & Cancellations & Remaining \\
\hline Annals of botany & Biology & 6 & 4 & 2 \\
\hline Annals of physics & Physics and Astronomy & 4 & 2 & 2 \\
\hline Astronomy and astrophysics review & Physics and Astronomy & 1 & 0 & 1 \\
\hline Atmospheric science letters & Physics and Astronomy & 0 & 0 & 0 \\
\hline Biochemical and biophysical research communications & Medicine & 6 & 3 & 3 \\
\hline Biochemistry & Medicine & 9 & 7 & 2 \\
\hline Brain and cognition & Psychology & 5 & 2 & 3 \\
\hline Bulletin of engineering geology and the environment & Geology and Geophysics & 3 & 1 & 2 \\
\hline Bulletin of volcanology & Geology and Geophysics & 2 & 1 & 1 \\
\hline Cognitive psychology & Psychology & 8 & 6 & 2 \\
\hline Current microbiology & Biology & 4 & 3 & 1 \\
\hline Developmental biology & Medicine & 4 & 3 & 1 \\
\hline Environmental geology & Geology and Geophysics & 6 & 4 & 2 \\
\hline Environmental management & Environmental Studies & 8 & 4 & 4 \\
\hline Environmental science and technology & Engineering & 6 & 5 & 1 \\
\hline Epilepsy and behaviour & Psychology & 1 & 0 & 1 \\
\hline Hydrogeology journal & Geology and Geophysics & 2 & 1 & 1 \\
\hline International journal of earth sciences & Geology and Geophysics & 1 & 0 & 1 \\
\hline Journal of catalysis & Engineering & 4 & 2 & 2 \\
\hline Journal of comparative economics & Economics & 3 & 2 & 1 \\
\hline Journal of economic theory & Economics & 5 & 4 & 1 \\
\hline Journal of environmental economics and management & Economics & 5 & 3 & 2 \\
\hline Journal of experimental child psychology & Psychology & 8 & 5 & 3 \\
\hline Journal of experimental social psychology & Psychology & 7 & 5 & 2 \\
\hline Journal of geodesy & Geography & 3 & 1 & 2 \\
\hline Journal of molecular biology & Biology & 5 & 3 & 2 \\
\hline Journal of molecular biology & Medicine & 5 & 3 & 2 \\
\hline Journal of physics $A$ & Physics and Astronomy/Engineering & 5 & 4 & 1 \\
\hline Journal of physics B & Physics and Astronomy/Engineering & 4 & 3 & 1 \\
\hline Journal of physics $D$ & Physics and Astronomy/Engineering & 4 & 3 & 1 \\
\hline Journal of physics $\mathrm{G}$ & Physics and Astronomy/Engineering & 2 & 1 & 1 \\
\hline Journal of physics: condensed matter & Physics and Astronomy/Engineering & 3 & 2 & 1 \\
\hline Journal of research in personality & Psychology & 6 & 5 & 1 \\
\hline Journal of sound and vibration & Engineering & 2 & 0 & 2 \\
\hline Meteorology and atmospheric physics & Physics and Astronomy/Geography & 2 & 1 & 1 \\
\hline
\end{tabular}


Mineralogy and petrology

Oecologia

Proteome

Pure and applied geophysics

Quaternary research

Virology
Geology and Geophysics

Biology

Biology

Geology and Geophysics

Geology and Geophysics

Medicine

$\begin{array}{rccc} & 1 & 0 & 1 \\ & 5 & 3 & 2 \\ & 0 & 0 & 0 \\ & 2 & 1 & 1 \\ & 5 & 3 & 2 \\ \text { percentages } & 5 & 3 & 2 \\ \text { totals } & 167 & 103 & 64 \\ & & 62 & 38\end{array}$

Table 1 shows that the number of current print subscriptions of core CNSLP titles, in the responding libraries, had definitely decreased. Generally, where there used to be several current print subscriptions, there were now just a few; where there used to be a few current print subscriptions, there were now just one or two. At the least, however, all of these journals are still available in print somewhere in Canadian university libraries.

\section{Survey Results, Part Two - Harcourt}

The detailed survey of the Harcourt participants revealed results that were akin to those found in the CNSLP studies.

\section{- Just over half of the participating institutions responded in some way.}

This was better than the response rate from the CNSLP members but there are only 15 Canadian medical school libraries, as opposed to 64 members in CNSLP.

\section{Quantitative Responses}

All the responding libraries had some current subscriptions to Harcourt print journals before the agreement. The numbers of ranged from 24 to 134 per library, with an average of 54.

$62 \%$ of the print subscriptions had been cancelled, with three libraries reporting that they had cancelled $100 \%$ of their journals and five reporting cancellations of greater than $75 \%$.

On the storage issue, the results mimicked the CNSLP responses. Only one of the Harcourt participants who returned the survey had placed cancelled journals in storage. 


\section{Qualitative Responses}

The replies to the cancellation and storage decision questions in the Harcourt project were virtually identical to those gathered from the CNSLP participants. Cost was the major reason for cancellation, along with supporting the switch to the electronic journal, while storage was listed as a consideration but not a step that is being actively taken by most libraries.

\section{Individual Harcourt Journals}

As was done with the CNSLP journals, University of Calgary subject librarians selected a small group of key Harcourt journals and this list was compared to the Excel spreadsheet of all journal holdings for the Harcourt libraries. A list of the active subscriptions for these core titles before and after the implementation of the Harcourt deal was produced and is featured in table 2.

TABLE 2. Pre- and Post-Cancellation Holdings for Some Key Harcourt Journals

\begin{tabular}{llcccc|}
\hline \multicolumn{1}{|c|}{ Title } & Discipline & Before & Cancellations & Remaining \\
\hline Archives of psychiatric nursing & Nursing & 4 & 3 & 1 \\
Clinical pharmacology and therapeutics & Medicine & 7 & 6 & 1 \\
Gastroenterology & Medicine & 7 & 5 & 2 \\
Heart and lung & Nursing & 6 & 4 & 2 \\
Hepatology & Medicine & 4 & 2 & 2 \\
Journal of allergy and clinical immunology & Medicine & 5 & 4 & 1 \\
Journal of pediatric nursing & Nursing & 5 & 3 & 2 \\
Nursing outlook & Nursing & 6 & 3 & 3 \\
& totals: & 44 & 30 & 14 \\
& percentages: & & 68 & 32
\end{tabular}

The figures for the key Harcourt journals are very similar to those for their CSNLP counterparts. If anything, the Harcourt cancellations were a bit deeper than the CNSLP reductions.

\section{What Can (Or Should) Be Done?}

Based on this small study, it looks like a notable reduction in the number of current print journal subscriptions covered in the CNSLP and Harcourt e-journal packages has occurred. This appears to be happening with other "Big Deals" and in other locales as well; the author has seen many reports that suggest that the cancellation of print journal in favor of electronic access may be occurring widely in academic libraries ${ }^{4}$. At the least, if libraries aren't dropping duplicated print subscriptions yet, they are likely considering doing so. The ability to cancel 
print covered in electronic packages is a highly desired feature for many libraries; a survey of the Boston Library Consortium indicated that, on average, the highest-rated reason for subscribing to publisher e-journal packages was the print cancellation policy ${ }^{5}$.

Is this a positive or negative situation? From an access point-of-view, on one hand, in consortial e-journal deals, an electronic journal is available in many locations, both inside and outside institutions; there is likely more overall access available than in the print-only world of the recent past. On the other hand, the number of the corresponding print sets available is declining, perhaps alarmingly. In this light, is the mass cancellation of print subscriptions in favor of e-access a safe step?

Assuming that the situation as described is a bad thing and sometime in the near future there may be extremely reduced holdings of academic print journals in Canada (and elsewhere), perhaps with some titles not represented in any Canadian research library, what can be done? What options are available?

Here are two main ideas, Distributed Print Archiving and Back-up Repositories.

\section{Distributed Print Archiving}

In this plan, each participating library commits to retaining certain print journals e.g. Library A holds all the print subscriptions for one publisher, Library B has the subscriptions for another, etc. Essentially, this is a form of cooperative collection development.

The chief problem with this sort of arrangement is that cooperative collection development, aside from bulk purchasing of electronic products (mostly) and occasional projects on a small scale or local level, has largely been a failure. Very similar projects have been attempted in earlier years with little or no success $^{6}$. Why would distributed print archiving work now when it has not done so in the past? Perhaps better communications, in this now highly-connected world, would help?

Another difficulty is that there is a certain financial luxury to this idea. Only the larger and/or better-funded libraries are going to participate. Smaller libraries (and many of the larger ones!) simply cannot afford the format duplication that e-journal packages bring.

What about spreading the load even thinner? Perhaps a model could be borrowed from the world of digital archiving, such as LOCKSS: lots of copies keeps stuff safe ${ }^{7}$. There could be multiple subscriptions across the country (or the continent or even the world), with a fair amount of duplication, and with libraries keeping a varying number of subscriptions at each location. 
Again, there are problems with this notion. Many libraries cannot afford any duplication of journal titles and a project of this nature would require an awful lot of coordination, quite possibly beyond what was practical.

\section{Back-Up Repositories}

Backup locations are essentially large, key locations where many journals could be held perpetually (hopefully). These institutions would have a broad, regional, if not national or international, focus.

Here are some possible candidates from a Canadian perspective. All are already involved in some sort of repository role:

\section{Canada Institute for Scientific and Technical Information}

The Canada Institute for Scientific and Technical Information (CISTI) is the library for the National Research Council (NRC) of Canada and acts as the repository for science, technology, and medicine (STM) journals in Canada. Due to license agreements, they are required to retain current print journal holdings in order to fulfill their document delivery mandate. Accordingly, they expect to be buying print journals and keeping these for a long time. However, CISTI only deals with STM material; this would cover most (but not all) of the journals in the CNSLP and Harcourt deals but could be of little value for journal packages of a different (non-STM) nature. Basically, CISTI won't be backing up complete print journal packages, though they may get close in some cases.

It is also important to keep in mind that, even though CISTI is a national repository, it is a unit of the Canadian federal government. Accordingly, changing political situation could drastically alter CISTI's mandate. As well, CISTI is still susceptible to the financial and space pressures that all libraries face.

\section{National Library of Canada}

The National Library of Canada (NLC) is a repository for material produced in Canada and about Canada. On the journals side, the NLC keeps print journals forever, at least journals of Canadian origin. The National Library has cancelled journals in the recent past for financial reasons but these were non-Canadian titles. The NLC still has some non-Canadian journals but can't guarantee that these will be retained perpetually; "forever" applies to Canadian materials only. As a result, the NLC will not be able to back up complete (or even close-tocomplete) print journal packages.

There is also a question of the facilities at the National Library of Canada. With respect to the staff that has to work in and deal with such conditions, the main NLC building is in poor shape, experiencing an average of 7-8 water leaks a year. This does not bode well for physical preservation of print journals (or any other material). 
As well, as another agency of the Canadian federal government, the National Library could be subject to changing decisions in the political arena.

\section{University of Toronto}

The University of Toronto is the largest university in Canada. It boasts the largest academic library in the country, which receives the largest percentage of the institutional budget for a Canadian academic library. As of mid-2002, the University of Toronto Library had not cancelled print subscriptions for journals covered in electronic fulltext consortial deals and, as such, was acting as an unofficial or default print archive for some of these projects. Perhaps it could be the official back-up repository?

There are issues to keep in mind with this suggestion, of course. Like all libraries, the University of Toronto Library can be susceptible to funding and space pressures. As well, though the University of Toronto has a massive collection, it doesn't quite hold "everything"; in terms of academic e-journals, the University of Toronto may carry all of the print equivalents in e-journal packages.

\section{Center for Research Libraries}

The Center for Research Libraries (CRL) is a large cooperative collection management facility located in Chicago. The member libraries of the CRL are large academic libraries and large public libraries with a research focus. One of the major roles of the CRL is to act as a repository for print materials, especially those of more unique nature. The Center is already acting as a print archive for the journals in the JSTOR project. Perhaps the CRL could do the same for the print journals in other consortial arrangements?

Drawbacks to this idea exist. From a Canadian viewpoint, transporting material to storage in the United States might be a very difficult proposition, from both practical and "political" perspectives. The CRL is also member-driven and there are only a handful of Canadian CRL members; as a result, requests that are of more interest to Canadian members may not always come to fruition. Perhaps a Canadian CRL (or two or three) is needed?

\section{The British Library}

The British Library operates much like the National Library of Canada and CISTI. Accordingly, it may be possible to use the British Library as a print journal archive for Canadian consortial projects. On the other hand, the British Library may be too distant to rely upon for stable print journal back-up.

\section{Publishers}

On one hand, it seems sensible that the producers of print journals could also appropriately archive the issues. On the other hand, there are numerous potential difficulties with this route. Archiving would take much space and time, both of which, in the world of commercial publishing, equal money; the publishers 
would expect some sort of remuneration for their efforts. As well, they have no historical responsibility to provide physical archiving ${ }^{8}$. Publishers can go out of business, be purchased, and so on, all of which can lead to unstable situations; the backing up print journals is a responsibility that requires much stability. Finally, the publishing could easily look to the library world and say "isn't archiving of print journals your job"?

Additionally, it appears that with many journal publishers, especially larger ones, if they have an "archive" focus at all, it is in regard to their electronic journals. There are, of course, many questions as to how well publishers are able to fulfill this role, beyond providing access to back issues through the World Wide Web. Many "Big Deals" now include a "perpetual access" clause of some sort so that when a contract comes to an end, the participating libraries "own" the online material that they had access to during the time of the contract. What form this archival access will take is largely undetermined ${ }^{9}$; the print journal may still end up being the most secure form of "perpetual access". More will be seen as some of the initial e-journal agreements come to an end and are not renewed.

\section{Organizations and Associations}

Is there any role in print archiving for library organizations or associations, particularly at a national level? Possibilities may exist here but these groups could probably only do the legwork (organizing, arranging, developing policy, etc.); in the end, physical libraries or other locations would have to do the physical archiving. Organizations and associations could perhaps handle costs, as any repository would expect some sort of payment for its efforts.

\section{Does Anything Actually Need To Be Done?}

The assumption that underlies much of the discussion in this paper is that the situation presented by the collected data is not promising. But is this really the case? Does anything actually need to be done? Will the fabled last print journal set actually be lost and does it matter if it is? Is there adequate replacement and archiving by the electronic counterpart? Can libraries and their users live with electronic-only journals? Print and electronic journals can be quite different but, increasingly, it seems that they are different in that e-journal can often be defined as "print plus more" ("more" being live links in the bibliography and links to adjunct material, interactive supplements, data sets, etc.) Libraries could perhaps keep only the "enhanced" electronic version.

As always, there are many issues to consider when making such a decision:

What about the ability of the electronic version to be altered by the publisher (or others)? In a well-publicized event, a controversial article was removed from the electronic version of the journal Human Immunology in $2002^{10}$; if no paper 
version was available, that article could be lost for good, regardless of its merits or lack thereof.

What about journals being dropped from packages? This can be a chronic problem with third-party aggregators but it does occur with publisher-based packages as well (though perhaps not to the same extent as the third-party aggregators). Publishers can sell, merge, discontinue, or lose the right to publish titles. In the last year or so, a fair number of journals have disappeared from the publisher packages reported in this paper.

There is also the question of electronic archiving. Is this developed enough so that we can forget about print and rely on well-supported (and widespread) electronic access? There is much work being done in the area of digital archiving so perhaps solutions are pending. Conversely, there is a chance stable e-journal archives may not ever be widely available.

What about archiving in other formats? Microfiche and microfilm are wellestablished tools for providing access to journal backsets (and they take up minimal space); however, there are questions of the quality of the reproduction and most library patrons are not fond of using micro products ${ }^{11}$. Microfiche and microfilm can also sometimes be surprisingly expensive.

One last point to consider is that the purpose of some of these consortial e-journal projects is to facilitate the movement of journal collections to the electronic environment; this was one of the goals of CNSLP, for instance. A shift in library holdings from print journals to electronic journals may be an indication of success in a consortial project with such aims ${ }^{12}$. The responses from the survey reported in this paper indicate that this is not a primary consideration when making cancellation decisions about print titles but it may be a by-product of the cancellation process.

\section{Conclusion and Next Steps}

This paper has presented a small picture of the current print subscriptions in two Canadian consortial arrangements involving scholarly e-journal packages, the first part of the Canadian National Site Licensing Project and the Harcourt Health Sciences deal, along with a discussion of some related issues. From the data, it appears that, given the option to cancel titles, active print journals in consortia will be reduced in number, perhaps substantially.

More study of this subject is required, of course. Some other avenues of investigation include:

- Follow-up surveys of the CNSLP and Harcourt participants 
As the original data is now a year old, it might be wise to re-survey the initial respondents. The author has heard anecdotal evidence that the print cancellations have continued and have deepened.

- Extending the survey to other areas and other "Big Deals"

Studying other "Big Deals" in different geographic areas would allow for comparisons to the Canadian-based information gathered in the survey detailed here. The same steps are likely being taken by most libraries and for similar reasons but this should be confirmed and the information gathered and shared.

- Examining non-STM print journals covered in e-journal packages

The CNSLP and Harcourt packages are mostly comprised of science, technology, and medical journals. What are libraries doing with e-journal packages that are more social sciences and arts and humanities based or that cover a wide range of disciplines? Are the print counterparts to these collections more likely to be retained?

- Extending the survey to non-university libraries

The survey discussed here focused on scholarly journals in university libraries. Is something similar happening in public libraries? (from a few conversations with public librarians, mostly in Alberta and Ohio, the author has found that public libraries don't seem to have cancelled print journals as extensively as their university counterparts have). What is happening in other types of academic libraries or in special or school libraries?

- More study of the implications of cancellation decisions.

The mass cancellation of print journals represents a big step that could have serious repercussions for libraries in terms of both long and short-term access to scholarly resources. Accordingly, further investigation of the effects of dropping subscriptions is definitely warranted; this paper is just a brief report, an early assessment in a period of great change.

In the end, the issue of print journal cancellations in light of e-journal packages and the resulting questions relating to the archiving of print journals will be on the agendas of many libraries for a while to come. At the same time, this is not necessarily a difficult issue to deal with. With a cooperative spirit and some inventiveness, the library community should be able to find ways to retain and maintain required print journal subscriptions (and then deal with the likely more tricky issue of e-journal archiving). 


\section{REFERENCES}

1. Among other articles, see:

Carol Hansen Montgomery. "'Fast Track"' Transition to an Electronic Journal Collection: A Case Study," New Library World 101/7 (2000): 294-303. $<$ www.emeraldinsight.com/0307-4803.htm > [1/6/03]

Carol Hansen Montgomery and JoAnne L. Sparks. "The Transition to an Electronic Journal Collection," Serials Review 26/3 (October 2000): 4-18. $<w w w . s c i e n c e d i r e c t . c o m>(27 / 11 / 00)[1 / 6 / 03]$

Brian Kenney. "Drexel's (Almost) All-E-Journal Collection," Library Journal 127/17 (Fall 2002): 4.

Carol Hansen Montgomery and Donald W. King. "Comparing Library and User Related Costs of Print and Electronic Journal Collections," D-Lib Magazine 8/10 (October, 2002) <www.dlib.org/dlib/october02/montgomery/10montgomery.html> [1/6/03]

Donald W. King and Carol Hansen Montgomery. "After Migration to an Electronic Journal Collection," D-Lib Magazine 8/12 (December, 2002) $<$ www.dlib.org/dlib/december02/king/12king.html [1/6/03]

2. Web of Science from the Institute of Scientific Information (ISI) was also part of phase one of CNSLP. Phase two was an agreement for access to Elsevier's ScienceDirect journals and came into force in January 2003. More information about CNSLP is located at <www.uottawa.ca/library/cnslp/>.

3. Christa Easton. "Doubly Bold - Replacing Print Journals With Electronic Versions," Serials Review 27/3-4, (2001), 91-101.

4. Among others, some articles dealing with print cancellation projects include:

Nancy Sprague and Mary Beth Chambers. "Full-Text Databases and the Journal Cancellation Process," Serials Review 26/3 (October 2000), 19-31. $<$ http://www.sciencedirect.com/> [1/6/03]

Karen Rupp-Serano, Sarah Robbins, and Danielle Cain. "Canceling Print Serials in Favor of Electronic: Criteria for Decision-Making," Library Collections, Acquisitions, and Technical Services 26/4 (Winter 2002), 369-378. $<$ http://www.sciencedirect.com/> [1/21/03]

Sulekha Kalayan. "Non-Renewal of Print Journal Subscriptions That Duplicate Titles in Selected Electronic Databases: A Case Study," Library Collections, Acquisitions, and Technical Services 26/4 (Winter 2002), 409-421. $<$ http://www.sciencedirect.com/> [1/21/03]

5. Jonathan Nabe. "E-Journal Bundling and Its Impact on Academic Libraries: Some Early Results," Issues in Science and Technology Librarianship 30 (Spring 2001) $30<$ istl.org/istl/01-spring/article3.html > [1/6/03]

6 . The University of Calgary was a partner in a distributed print archiving arrangement with other members of the Council of Prairie and Pacific University Libraries (COPPUL) in the late 1980s and early 1990s. The arrangement fell apart as journal prices rose steeply in the early years of that decade. Journal costs overcome the commitment to retention.

7. More information about LOCKSS can be found at <lockss.stanford.edu/> 
8. Donnelyn Curtis, Virginia M. Scheschy, and Adolfo R. Tarango. Developing and Managing Electronic Journal Collections: A How-to-do-it Manual for Librarians, No. 102-New York: Neal Schuman Publishers, 2000.

9. At the time of writing, the author was waiting for the arrival of a DVD of the back-file content of the 59 Kluwer Law International journals that were sold to Aspen Publishers in August 2002. The University of Calgary Library had a license to this material, with a "perpetual access" clause. How usable this DVD is going to be is unknown.

10. A summary of the Human Immunology situation is: T. Scott Plutchak. "Sands Shifting Beneath Our Feet," Journal of the American Medical Association 90/2 (April 2002): 161-163.

$<$ www.pubmedcentral.gov./articlerender.fcgi?artid=100760> [5/7/02]

11. At the University of Calgary, anecdotal evidence suggests that micro products are clearly in $3^{\text {rd }}$ place in terms of use after electronic and paper formats. Many patrons will simply not use microfilm or microfiche, even if it is the only format available.

12. Telephone conversation with Deb de Bruijn, Executive Director, CNSLP, and Ben Schmidt, Technical Director, CNSLP [6/12/02].

\section{APPENDIX ONE}

The first survey was posted to the CNSLP email list on January 17, 2002. The recipients of this message were the main contact persons (mostly collections librarians) at each of the 64 Canadian university libraries participating in CNSLP. The message was short and informal:

$\mathrm{Hi}$. I was wondering what everyone is doing with the print versions of the CNSLP journals that you hold? Are you canceling or keeping? If you're not retaining the print, are you leaving the backsets on the shelves or are you putting the backsets into storage? I've heard some of what other CNSLP participants are doing (it seems to be a mixed bag) but I thought it would be useful to find out what everyone's plans are.

Thanks.

Andrew

Andrew Waller

Serials Librarian

Collections Services

University of Calgary Library

waller@ucalgary.ca

(403) 220-8133 voice

(403) 284-2109 fax 
A short summary of the responses, repeated earlier in this paper, was sent to the CNSLP email list on February 20, 2002.

The second survey was sent to the CNSLP participants on June 3, 2002, again via the CNSLP email list. The message was as follows:

Earlier this year, I sent out a message asking some questions about the disposition of print CNSLP journals in your libraries. I received some very interesting results, which I forwarded to the list in summary. These results have prompted me to do some more detailed investigating, which I am presenting to you in this message.

I will be including the results of this survey in a paper that I will be presenting at the Pre-Conference Session on the Future of Collections Work in Canadian Libraries in Halifax later this month. The paper is entitled "Print Journal Holdings in Consortial Projects".

I will share both the results of this survey and the paper with all of you later this summer. All releases of data will not include any mention of institutions or individuals.

I have attached an Excel file that lists the journals that are presently part of the CNSLP package, along with some information about the online holdings. In this file, could you indicate for each of the titles:

- If your library held a current print subscription before CNSLP

- If your library has cancelled the print subscription or plans to do so soon

- If your library has moved backset print journals to storage or plans to do so soon

Please mark this information in the last three columns with a "yes", Y, X, or something that indicates your choices clearly.

In addition, if you could briefly answer two questions:

1) If your library has cancelled any print subscriptions, what were your reasons?

2) If your library has moved any backsets to storage, what were your reasons? 
Return by email is preferred but you can print out the list and fax the completed version to me (403-284-2109). Please send all submissions to me by Friday, June 14 [note: A few submissions were also accepted after this date but the data was not included in the presentation at the collections pre-conference on June 19, 2002. The data has been incorporated into this paper]

I realize that completing this could take some time. If you do not have the time to go through the list title-by-title, I will gladly accept summaries of the three columns and answers to the two questions.

I do hope that many of you will complete this survey. The more responses I receive, the more meaningful the results will be. Hopefully, we can create a picture of the active print journals subscriptions in CNSLP libraries and can use these results in our collection management.

A note about the accuracy of the titles on this list: The list should be up-todate. However, it is possible that some journals are missing and some journals that are no longer part of CNSLP are included. This should not affect the overall picture that I am hoping to present.

Please email or call me if you have any questions or comments.

Much thanks for your assistance.

Andrew

Andrew Waller

Serials Librarian

Collections Services

University of Calgary Library

waller@ucalgary.ca

(403) 220-8133 voice

(403) 284-2109 fax

This message had an attachment, an Excel document that listed the 731 journals in the CNSLP package at that time. There were three sheets in this document; one for libraries to indicate which titles they held in print before CNSLP, one for indicating which titles they had cancelled or planned to cancel soon, and one for noting which titles had been placed in storage. The alphabetical list of journal titles was accompanied by basic publisher information and some information about the online holdings that were available to participating libraries. For the sake of brevity, a small segment of the 
amalgamated spreadsheet has been included here; the complete list is available upon request from the author.

\begin{tabular}{|c|c|c|c|c|c|c|}
\hline Springer & Analytical and Bioanalytical Chemistry & v.353, no.2, 1995 - & & & & \\
\hline Academic Press & Analytical Biochemistry & v.208, $1993-$ & & & & \\
\hline American Chemical Society & Analytical Chemistry & v.68, $1996-$ & & & & \\
\hline Royal Society of Chemistry & Analytical Communications & v.34, 1997 - v.36, 1999. & backsets only & & & \\
\hline Academic Press & Animal Behaviour & v.45, $1993-$ & & & & \\
\hline Springer & Animal Cognition & v.1, 1998 - & & & & \\
\hline Springer & Annales Geophysicae & v.14, no.10, 1996 - & & & & \\
\hline Springer & Annales Henri Poincare & v.1, 2000 - & & & & \\
\hline Academic Press & Annals of Botany & v.71, $1993-$ v.88, 2001. & backsets only & & & \\
\hline
\end{tabular}

The Harcourt survey also utilized email. As the author was less familiar with the collections contacts at Canadian medical school libraries, two approaches were followed. The main message about the survey was sent via an intermediary, to the Association of Canadian Medical Colleges libraries email list. Additionally, just to be careful, an email note was sent to the CNSLP contacts from universities with medical schools asking that the main message be passed to the appropriate person at the medical library. The main message read:

My name is Andrew Waller. I am the Serials Librarian at the University of Calgary library. I will be presenting a paper entitled "Print Journal Holdings in Consortial Projects" at the Pre-Conference Session on the Future of Collections Work in Canadian Libraries in Halifax later this month. As part of my presentation, I will be looking at what decisions were made regarding print subscriptions in recent consortial purchases of fulltext journal resources. I would like to include the Harcourt Health Sciences project in my study and am hoping that you can help me with this. (I am also looking at the journals in the Canadian National Site Licensing Project (CNSLP))

I have attached an Excel file that lists the journals that are presently part of the Harcourt package. In this file, could you indicate for each of the titles:

- If your library held a current print subscription before Harcourt

- If your library has cancelled the print subscription or plans to do so soon 
- If your library has moved backset print journals to storage or plans to do so soon

Please mark this information in the last three columns with a "yes", Y, X, or something that indicates your choices clearly.

In addition, if you could briefly answer two questions:

1) If your library has cancelled any print subscriptions, what were your reasons?

2) If your library has moved any backsets to storage, what were your reasons?

Return by email is preferred but you can print out the list and fax the completed version to me (403-284-2109). The list is set up for printing on legal size paper though some resizing may be required at your end.

Please send all submissions to me by Friday, June 14. One submission per institution.

I realize that completing this could take some time. If you do not have the time to go through the list title-by-title, I will gladly accept summaries of the three columns and answers to the two questions.

I will share both the results of this survey and the paper with all of you later this summer. All releases of data will not include any mention of institutions or individuals.

Please email or call me if you have any questions or comments.

Much thanks for your assistance.

Andrew

Andrew Waller

Serials Librarian

Collections Services

University of Calgary Library

waller@ucalgary.ca

(403) 220-8133 voice

(403) 284-2109 fax

Like the CNSLP survey, the Harcourt survey was also accompanied by an Excel spreadsheet that listed the 159 journals in the Harcourt Health Sciences 
package. Three similar sheets were included; one for libraries to indicate which titles they held in print before the Harcourt deal, one for indicating which titles they had cancelled or planned to cancel soon, and one for noting which titles had been placed in storage. Again, a sample of this long list follows here; the complete spreadsheet is available upon request.

\begin{tabular}{|c|c|c|c|}
\hline Journal Title & $\begin{array}{c}\text { Print } \\
\text { Before } \\
\text { CNSLP }\end{array}$ & $\begin{array}{c}\text { Print } \\
\text { Cancelled }\end{array}$ & $\begin{array}{c}\text { Backsets } \\
\text { To } \\
\text { Storage }\end{array}$ \\
\hline
\end{tabular}

American Heart Journal

American Journal of Contact Dermatitis

American Journal of Emergency Medicine, The

American Journal of Kidney Diseases

American Journal of Obstetrics and Gynecology

American Journal of Orthodontics and Dentofacial Orthopedics

American Journal of Otolaryngology

Annals of Diagnostic Pathology

Annals of Emergency Medicine

Applied Nursing Research 